Journal of The Electrochemical Society, 152 (3) A645-A651 (2005)

\title{
Synthesis and Performance of Sol-Gel Prepared Ni-YSZ Cermet SOFC Anodes
}

\author{
Peter G. Keech,* Danielle E. Trifan, and Viola I. Birss**,z
}

Department of Chemistry, University of Calgary, Calgary, Alberta, Canada

Sol-gel derived (SD) NiO-YSZ particles were formed from metallic nitrate and butoxide precursors, and after heat-treatment at $1000^{\circ} \mathrm{C}$, the $\mathrm{NiO}$ and yttria-stabilized zirconia (YSZ) average particle sizes were found to be less than 50 and $30 \mathrm{~nm}$, respectively, as measured using X-ray diffraction and transmission electron microscopy. In both cases, small particles were observed as larger agglomerates, up to $100 \mathrm{~nm}$ in size. The SD powders were suspended in ethanol and sprayed onto YSZ disks, roughened with a thin layer of pure SD YSZ to improve active layer adhesion. Electrochemical evaluation (low- and high-field cyclic voltammetry and impedance spectroscopy) was carried out in a half-cell configuration at $800^{\circ} \mathrm{C}$ in a $3 \% \mathrm{H}_{2} \mathrm{O} / \mathrm{H}_{2}$ mixture. The exchange current density, obtained from all three methods, was found to agree only if a two-step hydrogen oxidation reaction was assumed, and the relatively low Tafel slope obtained suggests that the second electron-transfer step may be rate limiting. By comparison with ceramic grade (CG) Ni-YSZ, our results indicate an initial tenfold higher performance for the SD Ni-YSZ. However, a gradual loss of performance was observed for the SD electrodes that was not seen with the CG materials, possibly attributed to the thinness of the SD active layer.

(C) 2005 The Electrochemical Society. [DOI: 10.1149/1.1855875] All rights reserved.

Manuscript submitted July 8, 2004; revised manuscript received August 5, 2004. Available electronically February 1, 2005.

Solid oxide fuel cells (SOFCs) continue to garner interest for use in stationary power systems due to their low $\mathrm{SO}_{x}, \mathrm{NO}_{x}$ emissions and high efficiencies. ${ }^{1}$ Composite cermet anodes, composed of $\mathrm{Ni}$ and yttria-stabilized zirconia (YSZ), are widely used for prototype SOFCs due to their low cost and high catalytic activity, ${ }^{2}$ despite some reported problems associated with stability. ${ }^{3}$ Mechanical mixing of ceramic grade $\mathrm{NiO}$ and YSZ powders is often selected as a technique for fabrication of these anodes ${ }^{4}$ due to its simplicity. However, disadvantages of this approach include particle sintering, ${ }^{5}$ which decreases the catalytic area, and segregation of $\mathrm{NiO}$ and $\mathrm{YSZ}$ particles, which can cause an uneven distribution of the Ni catalyst following anode reduction. ${ }^{6}$ Consequently, recent strategies related to SOFC anode synthesis have focused on the chemical coproduction of homogeneous mixtures of $\mathrm{NiO}$ and $\mathrm{YSZ}$, thereby eliminating these problems. ${ }^{6}$

Several of the recently investigated strategies for the formation of homogeneous NiO-YSZ powders include self-assembly ${ }^{7}$ and the use of sol-gel (SG) and sol-derived (SD) chemistry, ${ }^{6}$ due to the relative simplicity and low cost of these synthetic approaches. Using the SG method, chemical precursors of YSZ and $\mathrm{NiO}$ have been combined in glycol and then dried to form a porous cake of $\mathrm{NiO}$ and YSZ powders. ${ }^{8}$ While being a homogeneous mixture, the $\mathrm{NiO}$ and YSZ powders produced using this approach are also nanoparticulate, a promising characteristic for fuel cell electrocatalysts. In addition to the increased surface area to mass ratio expected when particle size is reduced, nanomaterials of this kind typically offer enhanced physical properties when compared to their larger particle size counterparts, e.g., ceramic-grade (CG) materials. These properties include strength, hardness, electrical resistivity, specific heat, etc., ${ }^{9}$ and a decreasing tendency to sinter or undergo other catalyst deactivation processes.

While offering much promise from a synthetic point of view, SD $\mathrm{Ni}$-YSZ anodes have undergone little in the way of performance testing. Only the most rudimentary electrochemical tests ${ }^{10}$ have been performed on any of these materials, and none have specifically targeted SOFC anode performance. This paper represents the first detailed study of the synthesis and electrochemical performance of Ni-YSZ SD anodes. We show that for our material, a mixture of $\mathrm{SD} \mathrm{NiO}$ and YSZ, with particle sizes ranging from 30 to $45 \mathrm{~nm}$, there is a significant performance improvement compared to CG materials, as measured during electrochemical testing at $800^{\circ} \mathrm{C}$ in a 97:3 $\mathrm{H}_{2}: \mathrm{H}_{2} \mathrm{O}$ atmosphere. This improved performance is most sig-

\footnotetext{
* Electrochemical Society Student Member.

** Electrochemical Society Active Member.

z E-mail: birss@ucalgary.ca
}

nificant during the early stages of testing, where more than a tenfold higher activity is observed for SD vs. CG anodes.

\section{Experimental}

$\mathrm{SD}$ powder synthesis.-Synthesis of $\mathrm{NiO}$ sol and $\mathrm{SD}$ powders.-75.6 mmol $\mathrm{Ni}\left(\mathrm{NO}_{3}\right)_{2} \cdot 6 \mathrm{H}_{2} \mathrm{O}$ (Alfa Aesar, 99.9985\%) was dissolved in $75 \mathrm{~mL}$ of ethanol and $10 \mathrm{~mL}$ of methanol for $4.5 \mathrm{~h}$ in a round-bottom flask, as described elsewhere. ${ }^{11}$ The solution was filtered and added to $160 \mathrm{~mL}$ of ethyl acetate to produce the $\mathrm{NiO}$ sol. NiO SD powder was prepared by a two-part heat-treatment, as described later. The sol was gradually heated, over $40 \mathrm{~min}$, in air to $230^{\circ} \mathrm{C}$, where it was held for $2 \mathrm{~h}$ and then allowed to cool over several hours to room temperature. The resulting caked solid was then ground to powder using a mortar and pestle and then heated over $1.5 \mathrm{~h}$ in air to $1000^{\circ} \mathrm{C}$, where it was held for $2 \mathrm{~h}$ before allowing it to gradually cool to room temperature over several hours.

Synthesis of 8\% YSZ sol and SD powders.-5.6 mmol of Y $\left(\mathrm{NO}_{3}\right)_{3} \cdot 6 \mathrm{H}_{2} \mathrm{O}$ (Alfa Aesar, $99.9 \%$ ) were dissolved in $20 \mathrm{~mL}$ of isopropanol. This solution was added to a vessel containing $64 \mathrm{mmol}$ of $\mathrm{Zr}(n-\mathrm{BuO})_{4} \cdot \mathrm{BuOH}$ (Alfa Aesar, $28 \% \mathrm{ZrO}_{2}$ in butanol solution) dissolved in $76 \mathrm{~mL}$ of isopropanol. The synthesis is based on the method of Kim et al., which involves the same starting materials and solvents, but also includes acetic acid. ${ }^{12}$ The combined solution was stirred for $18 \mathrm{~h}$ at room temperature under atmospheric conditions to produce the YSZ sol. If exposed to the atmosphere for more than $18 \mathrm{~h}$, the sol undergoes gelation, but this process can be inhibited through the addition of small quantities of nitric acid. The YSZ SD powder was prepared following the same two-part heattreatment as described for the $\mathrm{NiO}$ SD powder, starting with the acid-stabilized sol.

Synthesis of NiO-YSZ composite sol and SD powders.-The composite sol was prepared by mixing the $\mathrm{NiO}$ and YSZ sols together in known molar ratios. With no further treatment, a gel formed after $0.5-1 \mathrm{~h}$ in air. Addition of concentrated $\mathrm{HNO}_{3}$ was found to increase time to gelation but does not eliminate it. NiOYSZ SD powder was prepared by the two-part heat-treatment described.

Preparation of electrochemical test cells.-Preparation of YSZ electrolytes. $-0.5 \mathrm{~mm}$ YSZ electrolyte disks were prepared by pressing $1 \mathrm{~g}$ quantities of $8 \%$ YSZ ceramic-grade (CG) powder (Tosoh, $99.7 \%$ ) in a $25 \mathrm{~mm} \mathrm{X-ray} \mathrm{fluorescence} \mathrm{(XRF)} \mathrm{die} \mathrm{to} 5000$ psi. To improve the adhesion of the anode layer to these YSZ disks, it was necessary to form a YSZ "anchoring layer". Consequently, the YSZ disks were heated to $\sim 80^{\circ} \mathrm{C}$ and sprayed with an air- 
nebulized solution containing $\sim 1 \mathrm{~g}$ of SD YSZ powder in $20 \mathrm{~mL}$ of ethanol. These modified disks were then sintered in air at $1350^{\circ} \mathrm{C}$ for $4 \mathrm{~h}$.

Application of NiO-YSZ anodes and other electrodes to YSZ electrolyte.-1 g of 50:50 (mol) YSZ:NiO SD powders was suspended in $20 \mathrm{~mL}$ of ethanol and air-nebulized and sprayed over a circular area $\left(0.40 \mathrm{~cm}^{2}\right)$ on the masked YSZ disks. $1 \mathrm{~g}$ of pure SD $\mathrm{NiO}$ in $20 \mathrm{~mL}$ of ethanol was subsequently sprayed on top of the composite layer. During application of both of these layers, a significant amount of this material did not affix to the electrolyte, making quantification of the catalyst impossible at this point. Experiments are ongoing to optimize the application of the SD powders and to improve the thickness of the catalytic layer. The anode-coated YSZ disk was then heated over $1 \mathrm{~h}$ to $1100^{\circ} \mathrm{C}$, where it was held for $2 \mathrm{~h}$ before returning it to room temperature over several hours to produce the working electrode (WE). Reduction of the $\mathrm{NiO}$ anode material to $\mathrm{Ni}$ was carried out in an atmosphere of $\mathrm{H}_{2} / 3 \% \mathrm{H}_{2} \mathrm{O}$ for at least $2 \mathrm{~h}$ prior to electrochemical testing.

Pt was sputtered in two locations on the opposite side of the WE to serve as the counter and reference electrodes (CE and RE, respectively). The $0.83 \mathrm{~cm}^{2} \mathrm{CE}$ was positioned symmetrically opposite to the WE, while the $0.13 \mathrm{~cm}^{2} \mathrm{RE}$ was $2 \mathrm{~mm}$ from the $\mathrm{CE}$, as per the geometry recommended to avoid artifacts in electrochemical data. ${ }^{13}$

Preparation of ceramic grade NiO-YSZ composite anodes.—44:56 NiO (Alpha Aesar 99\%):8\% YSZ (Tosoh) were combined and ballmilled for $1 \mathrm{~h}$ in ethanol. This material was then added to glycerol, and the resultant paste was painted directly onto sintered YSZ disks in a circular region of $0.03 \mathrm{~cm}^{2}$ to form the WE. Following heat-treatment at $1450^{\circ} \mathrm{C}$ for $4 \mathrm{~h}$, a Pt $\mathrm{CE}$ and $\mathrm{RE}$ were sputtered onto the YSZ, prior to a second heat-treatment at $1100^{\circ} \mathrm{C}$ for $2 \mathrm{~h}$.

Characterization of $S D$ powders and thin films. $-X R D$ characterization.-X-ray diffraction (XRD) was performed on a Rigaku multiflex diffractometer (Department of Geology \& Geophysics, University of Calgary) equipped with a $\mathrm{Cu}$ target with an operating voltage and current of $40 \mathrm{kV}$ and $40 \mathrm{~mA}$, respectively. The scanning range was varied between 10 and $70^{\circ}$ at a rate of $2 \%$ min. The average crystallite size was calculated from peak broadening using Jade software (version 6.5).

Transmission electron microscopy characterization.-Transmission electron microscopy (TEM) was employed to characterize the NiO, YSZ and NiO-YSZ SD powders. Micrographs were obtained on either a Hitachi H-7000 or a Philips/FEI field emission TEM (Microscopy and Imaging Facility, University of Calgary); the latter also performed energy-dispersive X-ray (EDX) analysis. Samples for analysis were obtained by sonicating $20 \mathrm{mg}$ of the SD powder in $10 \mathrm{~mL}$ of ethanol, and then depositing small aliquots onto carbon-coated Cu TEM grids.

SEM analysis.-Scanning electron microscopy (SEM) was performed using a Philips/FEI ESEM, (Microscopy and Imaging Facility, University of Calgary), equipped with EDX capabilities. Samples with just the anchoring YSZ layer, as well as those with completed anodes produced from NiO-YSZ SD powders, were carbon-coated and examined. Top-down analysis was performed on both materials, while cross-sectional analysis was performed only on the anode layer to determine its thickness.

Electrochemical performance testing of Ni-YSZ anodes.-All electrochemical experiments were performed in a humidified $(3 \%$ water) hydrogen atmosphere at $800^{\circ} \mathrm{C}$. The presence of $\mathrm{H}_{2}$ ensured the reduction of $\mathrm{NiO}$ to $\mathrm{Ni}$ and served as the fuel for the anode reaction, while water was added to allow its reduction at the $\mathrm{CE}$ in these half-cell experiments.

For electrochemical testing, a special cell holder was designed to fit into the horizontal tube furnaces used to heat to the $800^{\circ} \mathrm{C}$ test environment; a schematic of the holder is shown in Fig. 1. The cell

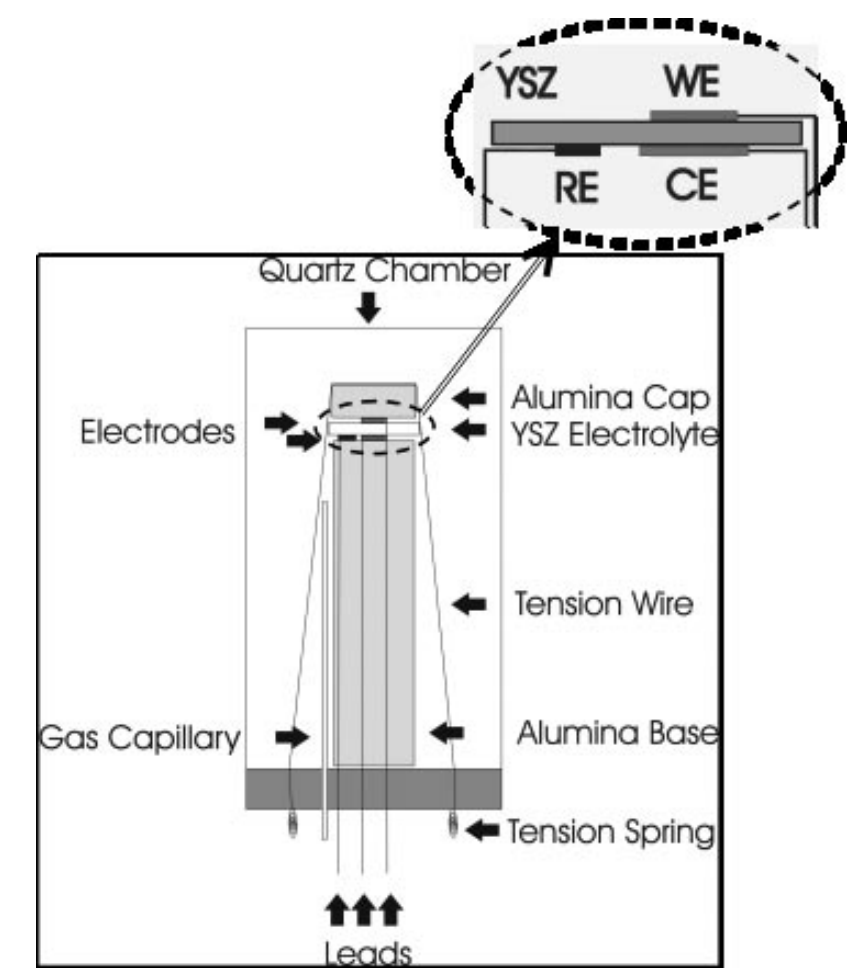

Figure 1. Schematic of electrochemical test cell.

holder consisted of an alumina rod on which the test cell was placed. The cell itself was covered by an alumina cap, which was held in place by a spring-loaded Monel tension wire. The cap served to press Pt mesh current collectors to the RE and $\mathrm{CE}$, and a Ni mesh to the WE. The current collectors were attached to Pt wires, which were fed through the $\mathrm{Al}$ stand via quartz tubes to the potentiostat. A closed-ended quartz tube attached to the $\mathrm{Al}$ stand isolated the test atmosphere, and the entire apparatus was wrapped with a Chromel shielding wire to minimize electrical noise from the tube furnace.

All standard electrochemical experiments were performed using a Solartron 1286 potentiostat with a Solartron 1255 frequency generator, using Scribner Corrware and ZPlot software. Cyclic voltammetry (CV) scans ranged from -300 to $500 \mathrm{mV}$ (uncompensated) $v s$. the RE, generally at $10 \mathrm{mV} / \mathrm{s}$. Electrochemical impedance spectroscopy (EIS), using a perturbation AC voltage of $10 \mathrm{mV}$ rootmean-square (rms), was carried out over a frequency range of $10^{6}-10^{-1} \mathrm{~Hz}$ at both the open circuit potential (OCP) and at dc biases of 100,200 , and $300 \mathrm{mV} v$ s. the OCP. It has been observed that inaccurate overpotential measurements can arise from even small electrode asymmetries during three-electrode measurements using thin electrolyte systems. ${ }^{14}$ However, these were minimized using the guidelines proposed by Chan et al. ${ }^{13}$ The distance between the edges of the RE and the $\mathrm{CE}$ was approximately four times the thickness of the electrolyte, which is more than the recommended factor of three. In addition, IR compensation was not performed in our work, as this has been shown to give incorrect approximations in asymmetric systems. ${ }^{13}$

\section{Results and Discussion}

$\mathrm{NiO}, \mathrm{YSZ}$, and NiO-YSZ SD powder characterization.-XRD characterization.- The XRD results for $\mathrm{SD} \mathrm{NiO}, 8 \% \mathrm{YSZ}$, and NiO-8\% YSZ powders, are shown as Fig. 2a-c, respectively. NiO was identified by matching three peaks to the data library (Jade, vers. 6.5), and the peak widths show the average crystallite size to be $45 \mathrm{~nm}$. Similarly, the formation of $8 \%$ YSZ was confirmed using two well-resolved peaks, as well as three peaks containing shoulders. To establish the average crystallite size of YSZ, shown to be 30 $\mathrm{nm}$, the widths of the two most resolved peaks were used. For the 


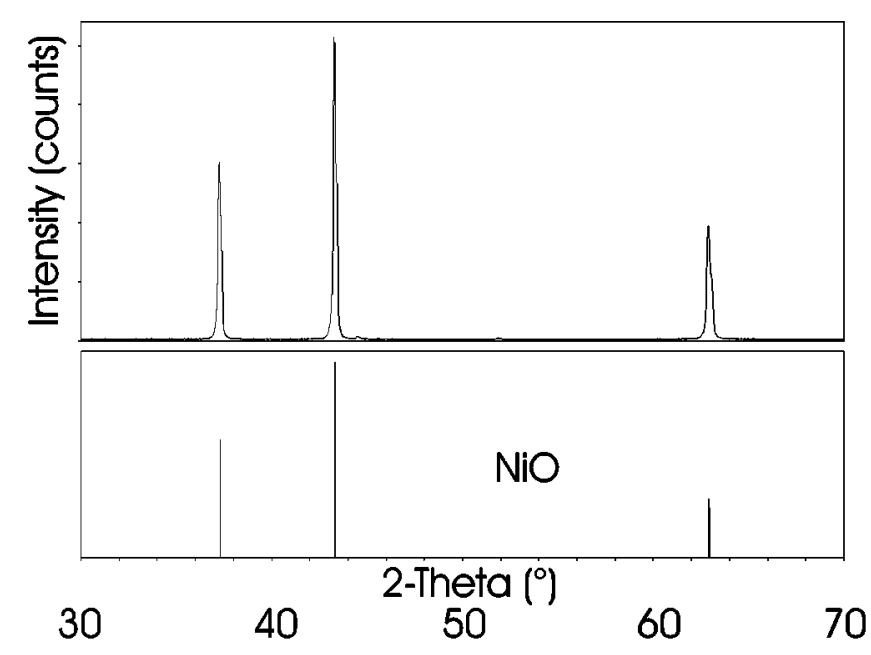

(a)

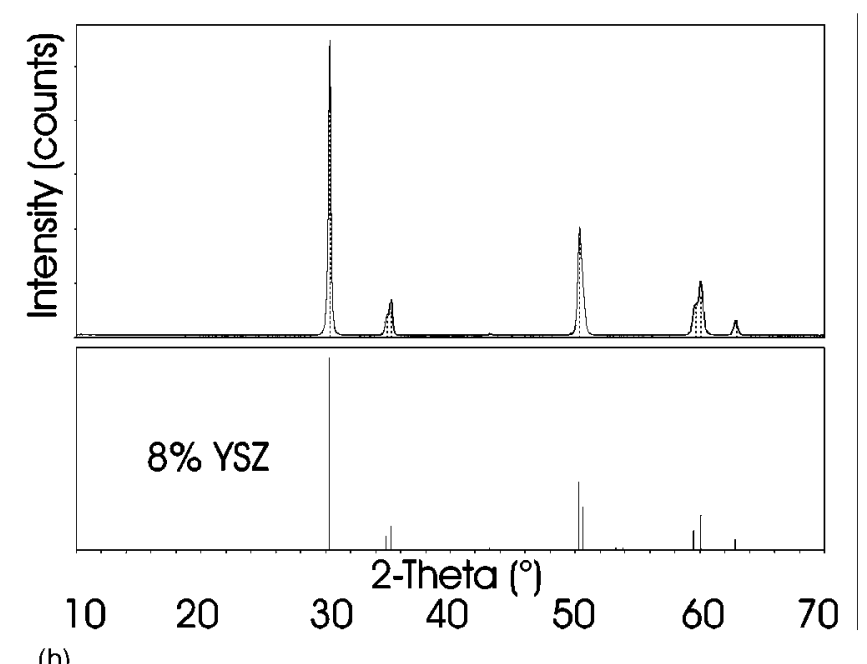

(b)

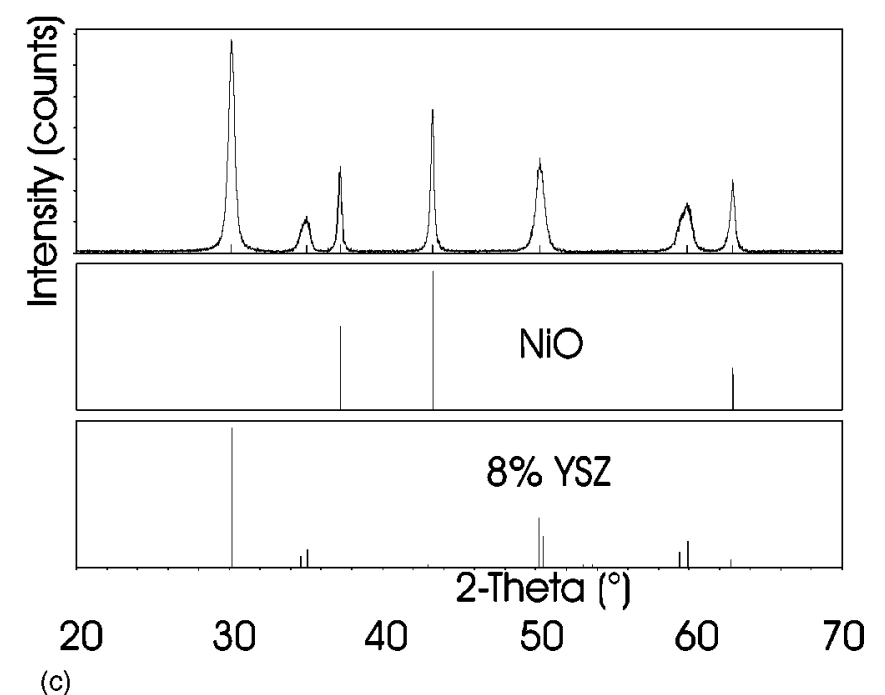

Figure 2. XRD pattern for (a) NiO, (b) $8 \%$ YSZ, and (c) 1:1 NiO:8\% YSZ $\mathrm{SD}$ powders.

composite NiO-YSZ SD powder, average crystallite sizes were found to be $49 \mathrm{~nm}$ for $\mathrm{NiO}$ and $35 \mathrm{~nm}$ for YSZ, although the latter value was taken from a single peak to avoid overlapping peaks. While these measured values are encouraging in terms of the goal of synthesizing nanoparticulate compounds, it is necessary to compare these data with TEM results to distinguish crystallite and particle sizes.

TEM examination of NiO, YSZ, and NiO-YSZ SD powders.-Figure 3a shows a TEM micrograph of the NiO SD powder in which all of the particles are seen to be below $100 \mathrm{~nm}$ in size, with $47 \%$ of the particles being smaller than $20 \mathrm{~nm}$, and $95 \%$ less than $50 \mathrm{~nm}$ in size (Fig. 3b). These results are consistent with the average particle size seen by XRD of $45 \mathrm{~nm}$. The particles generally appear crystalline in nature, possessing relatively sharp, welldefined edges. Further, the largest particles appear to be composed of smaller ones, indicating a propensity for these materials to agglomerate.

As can be seen in Fig. 3c, the SD YSZ particles are not as well resolved spatially as $\mathrm{NiO}$ and instead appear to be agglomerates, many micrometers in length, composed of nanoparticles. Although the small particles appear noncrystalline in nature, with poorly defined edges, their size is estimated to range between 2 and $10 \mathrm{~nm}$. Even for the larger dark agglomerates in Fig. 3c, where small particles cannot be resolved, particle size is estimated to be below $50 \mathrm{~nm}$; this value can be considered a maximum particle size. These particle sizes compare well with the average crystallite size measured by XRD of $29 \mathrm{~nm}$, as they span from 2 to a maximum of $50 \mathrm{~nm}$.

The TEM image of the NiO-YSZ composite material, shown in Fig. 4a, clearly reveals the presence of nanoparticles. Significantly, EDX spot analysis proved to be sensitive enough to differentiate between them, in contrast to what was reported in a previous study. ${ }^{6}$ As examples, the EDX spectra of particles 1 and 2 are shown in Fig. $4 \mathrm{~b}$ and $\mathrm{c}$, respectively. Based on the EDX analysis of all of the particles, 1 and 3-5 are $\mathrm{NiO}$, while particle 2 is YSZ. The TEM analysis also shows the retention of the morphological characteristics of the individual phases, with the $\mathrm{NiO}$ component appearing more crystalline than the YSZ.

Similar particle sizes have been observed, using both XRD and TEM, for mixed SD powders of $\mathrm{Ni}$ and YSZ (originally $<10 \mathrm{~nm}$ in size) that have undergone heat-treatment and reduction at $650^{\circ} \mathrm{C}$ in hydrogen, i.e., 30-50 and $30 \mathrm{~nm}$, respectively. ${ }^{6}$ For similar SD materials that had undergone heat-treatment to $450^{\circ} \mathrm{C}$, the particle size was only 3 and $15 \mathrm{~nm}$ for YSZ and $\mathrm{Ni}$, respectively, but these increased to 8 and $25 \mathrm{~nm}$, respectively, when heat-treated to $600^{\circ} \mathrm{C}{ }^{8}$

Conventional $\mathrm{CG}$ anodes are derived from NiO/YSZ, having significantly larger particle size, e.g., $\sim 2 \mu \mathrm{m}$ for mechanically mixed powders, ${ }^{15}$ although ballmilling can produce samples where large particles show a fine structure below $50 \mathrm{~nm},{ }^{16}$ as measured using XRD. Particle sizes of $\sim 1 \mu \mathrm{m}$ are obtained for anode materials prepared using spray pyrolosis, ${ }^{17}$ and $250-800 \mathrm{~nm}$ when combustion synthesis is employed. ${ }^{18} \mathrm{NiO} / \mathrm{YSZ}$ powders synthesized using citrate/nitrate combustion are reported to exhibit crystallite sizes as low as $11 \mathrm{~nm}$ for $\mathrm{NiO}$ and $7 \mathrm{~nm}$ for $\mathrm{Ni}$ prior to heat-treatment, but the corresponding particle sizes have not been determined using TEM. ${ }^{19}$

Improving NiO-YSZ/YSZ interfacial properties.-Several synthetic strategies were employed during the initial preparation of SD NiO-YSZ anode materials. Initially, sols and alcohol solutions containing SD powder were directly aliquoted onto sintered YSZ disks and then heat-treated. Alternatively, NiO-YSZ SD powders were combined in glycerol and were screen-printed onto sintered YSZ disks, followed by heat-treatment. However, the adhesion of the SD anode materials and the relatively smooth YSZ electrolyte surface proved to be poor, and the anode layers simply flaked off during, or immediately after, heat-treatment.

Consequently, a new strategy was adopted in which an interlayer of SD YSZ was deposited on the YSZ disk prior to heat-treatment, ostensibly serving to roughen the YSZ surface. This was based on parallel successful efforts to similarly improve the interfacial properties of SG-derived lanthanum strontium manganite (LSM) cathode layers on YSZ disk electrolytes. ${ }^{20}$ Anodes constructed with this interlayer present were able to undergo heat-treatment, chemical re- 


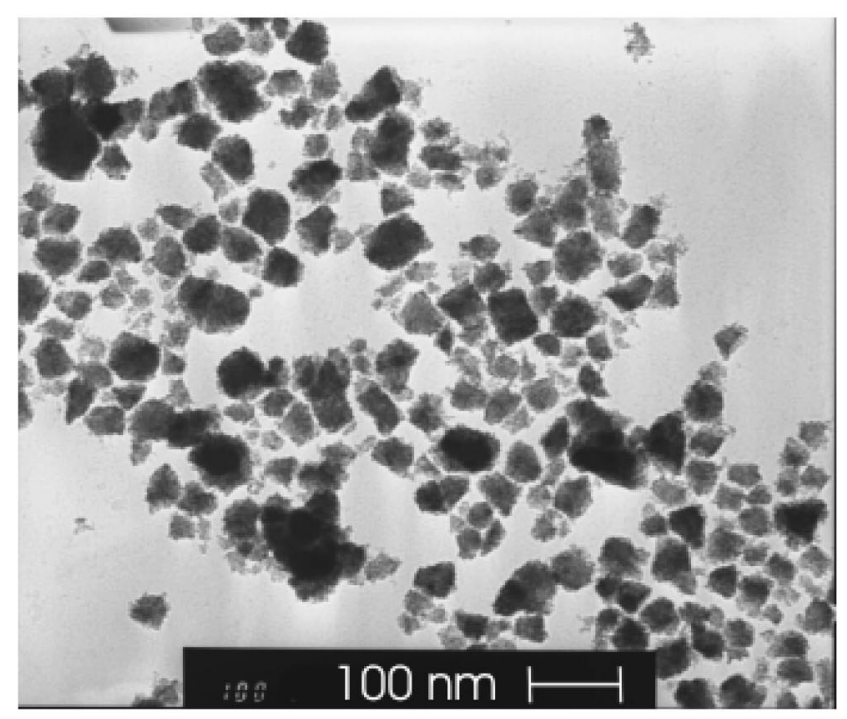

(a)

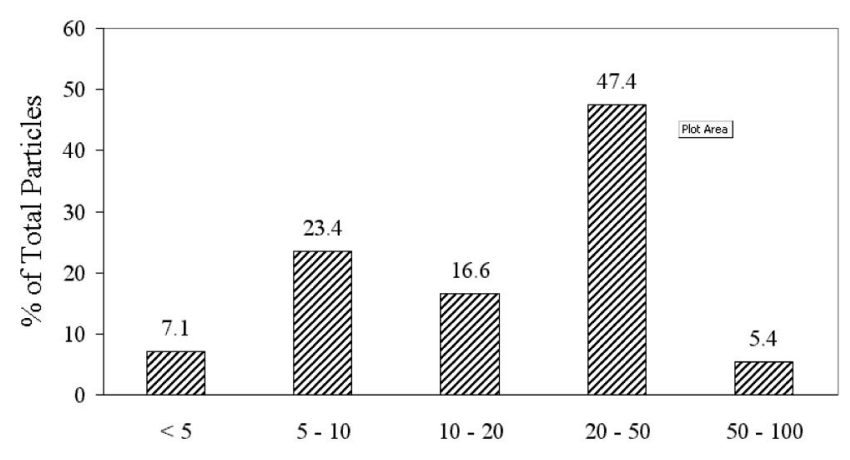

(b)

Largest Particle Diameter (nm)

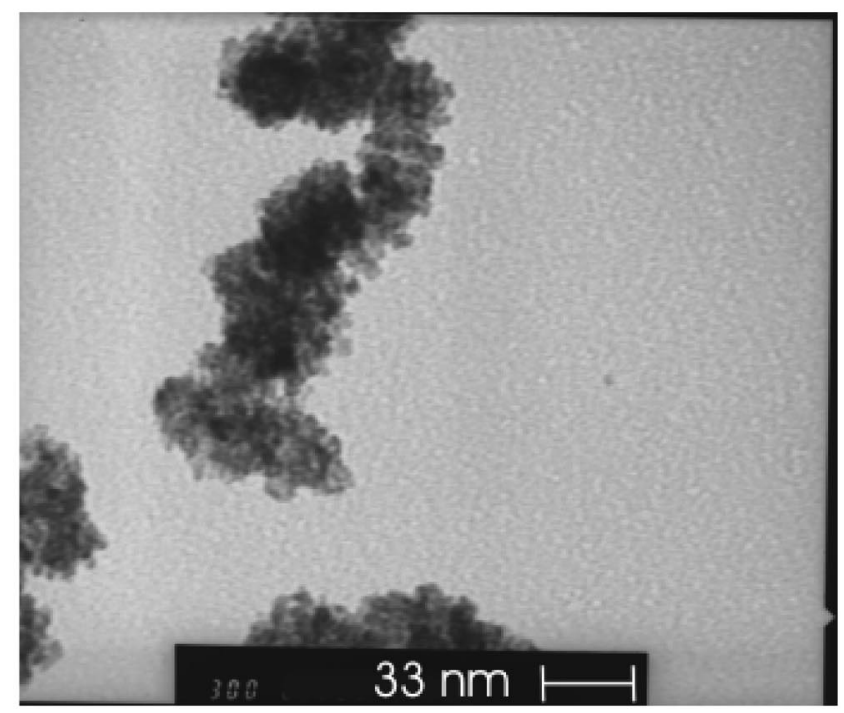

(c)

Figure 3. (a) TEM image of $\mathrm{NiO}$ powder, (b) histogram of $\mathrm{NiO}$ particle sizes, and (c) TEM image of $8 \%$ YSZ SD powder.

duction, and electrochemical performance testing, without any loss of the catalyst layer or any evidence of interfacial problems.

Figure 5 shows a secondary electron SEM image of the SD YSZ anchoring layer on a standard YSZ disk. Sub-micrometer-sized granular surface features are readily observable, indicating that the
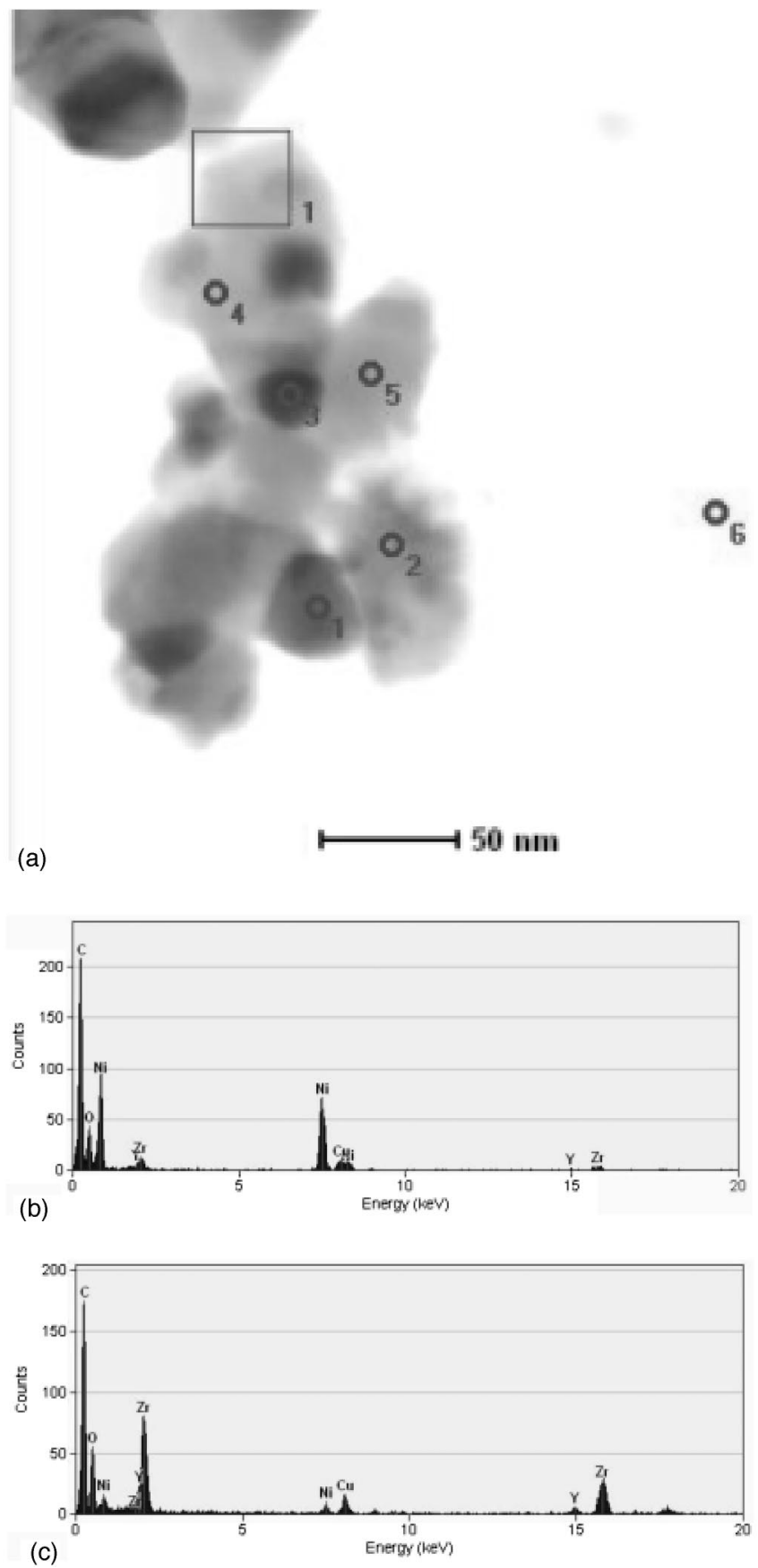

Figure 4. (a) TEM image of 1:1 NiO:8\% YSZ SD powder, and EDX data for (b) $\mathrm{NiO}$ and (c) $8 \%$ YSZ particles.

application of the anchoring layer was successful. In addition, much larger particles, up to several micrometers in diameter, are also seen, indicating a tendency for some of the YSZ to agglomerate, either during the spray deposition or heat-treatment steps.

SEM characterization of YSZ and NiO-YSZ SD anode materials.-Figure 6a shows a low-resolution, top-down backscattered SEM image of a SD anode, consisting of a layer of $\mathrm{NiO}$ on a NiO-YSZ composite layer, deposited on a modified YSZ electrolyte. As the image contrast indicates, the NiO layer is not entirely uniform in thickness or structure, as the underlying YSZ can be detected in some locations. Top-down EDX analysis performed on the NiO-coated YSZ anode showed a high YSZ signal at all locations. This observation is consistent with the presence of either a highly porous 


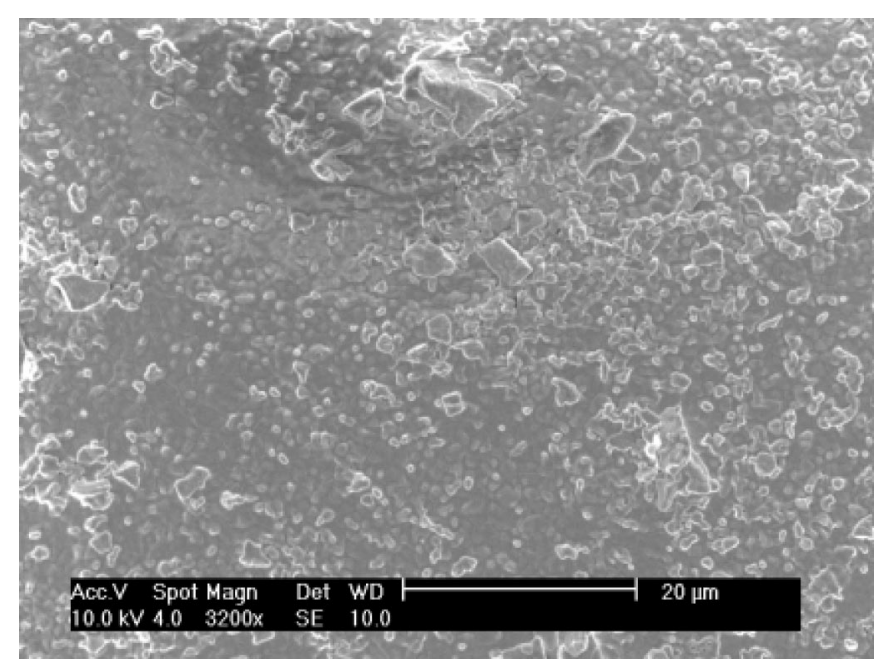

Figure 5. SEM image of YSZ anchoring layer on YSZ electrolyte disk.

or a very thin $\mathrm{NiO}$ layer, so cross-sectional analysis was performed

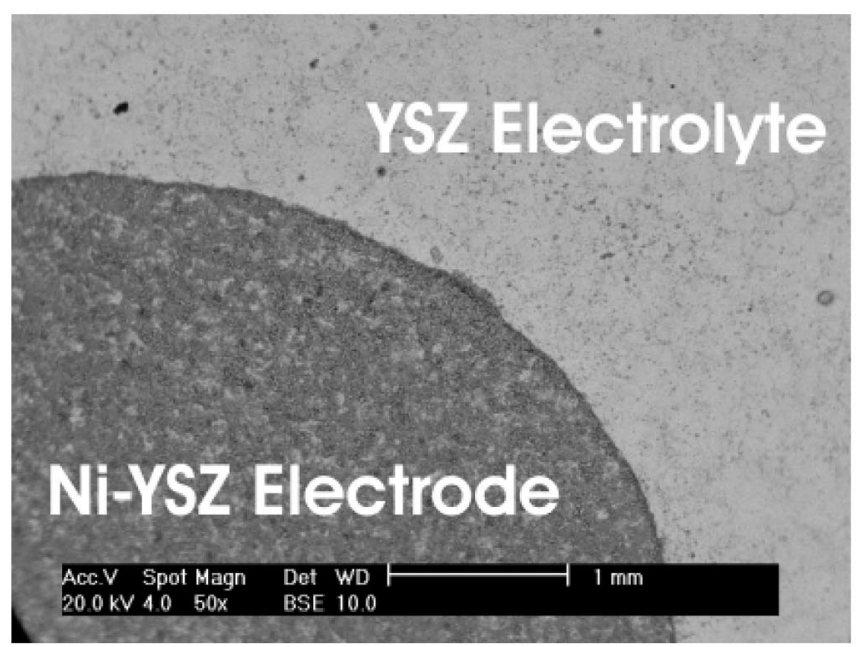

(a)

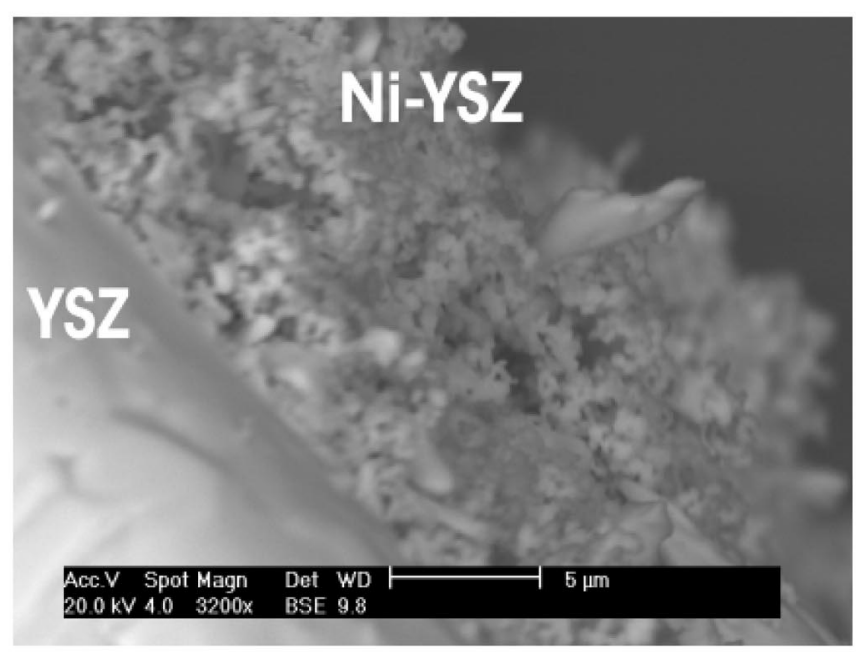

(b)

Figure 6. (a) Low-resolution SEM top-down view of NiO-YSZ electrode on YSZ electrolyte disk and (b) high-resolution SEM image of cross section of NiO-YSZ electrode on YSZ.
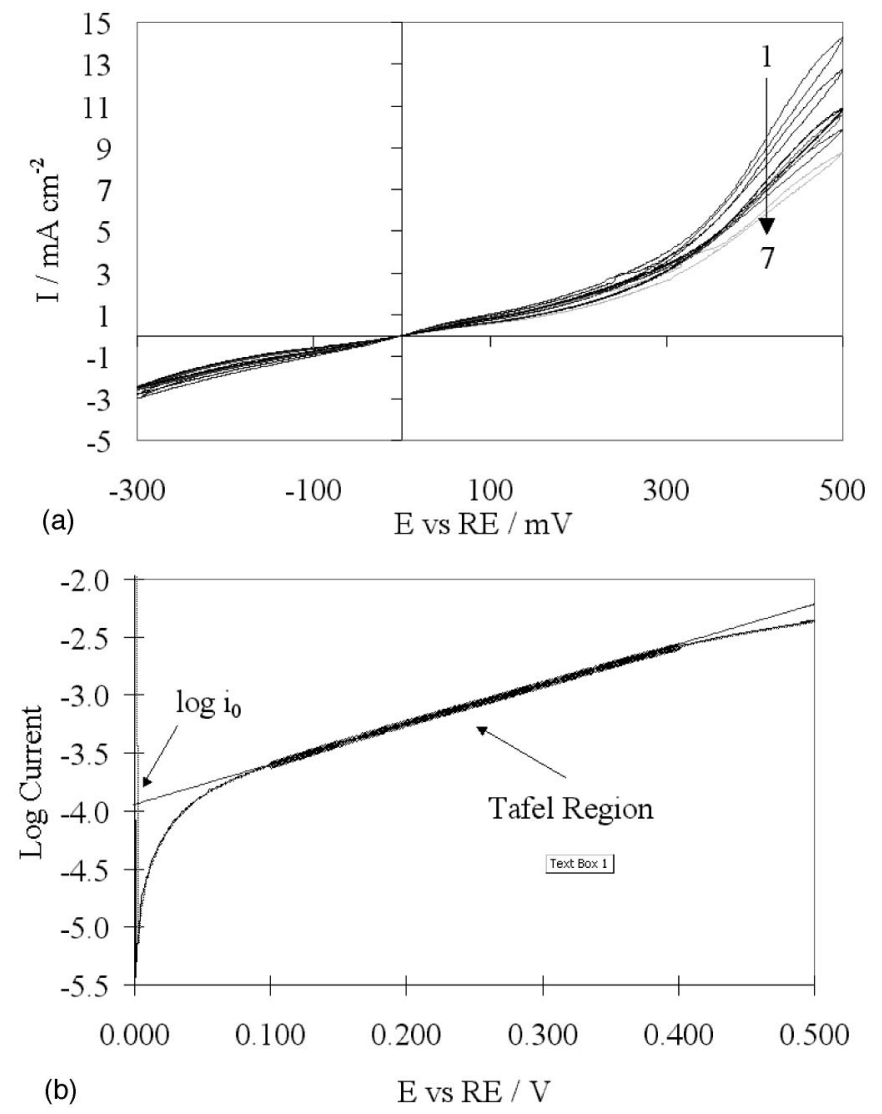

Figure 7. Typical CV (a) of $\mathrm{H}_{2}$ oxidation at SD NiO-YSZ electrode on YSZ disk electrolyte and (b) resultant Tafel plot at $10 \mathrm{mV} / \mathrm{s}$ in $97: 3 \mathrm{H}_{2}: \mathrm{H}_{2} \mathrm{O}$ at $800^{\circ} \mathrm{C}$.

as well. The cross-sectional images of the anode layer, shown in Fig. 6b, reveals a highly porous $\mathrm{NiO}$ structure and demonstrates that the $\sim 5-10 \mu \mathrm{m}$ layer is quite uniform in thickness.

Relatively little SEM analysis has been performed previously on electrodes fabricated from SD and related materials. More typically, materials have been characterized in their powder form using TEM and XRD methods, rather than as thin-film electrodes. When a citrate/nitrate combustion synthesis was employed, by mixing nitrate precursors and combusting them in a citrate matrix, it produced nanoscopic crystals of $\mathrm{NiO}$ and YSZ. SEM analysis of the ashes formed during this process ${ }^{19}$ showed the presence of ordered nanoparticles at high magnification, although only rough micron sized particles were seen at lower magnifications. In the case of ceramic grade NiO-YSZ, studied previously, cross-sectional SEM analysis ${ }^{21,22,23}$ showed a marked similarity to the images obtained in the present investigation, revealing a distinct porous anode layer on the much more dense electrolyte.

Electrochemical performance of SD Ni-YSZ anodes.-Typical $\mathrm{CV}$ scans during hydrogen oxidation at anodic potentials up to $0.5 \mathrm{~V}$ and water reduction between 0 and $-0.3 \mathrm{~V}$, at a SD Ni-YSZ anode deposited on a YSZ sol modified YSZ disk, are shown in Fig. 7a. These data were collected without IR compensation, which proved unnecessary due to the low series resistance present under these conditions. The CVs show approximately exponentially increasing currents as a function of potential, consistent with activationcontrolled kinetics. At high positive potentials, the current appears to level off somewhat, possibly as hydrogen oxidation becomes limited by mass transfer. Figure $7 \mathrm{a}$ also shows that there is a decrease in performance of the Ni-YSZ SD anode with continued cycling. The 
cause of this performance degradation is unknown but may be related to the relative thinness of the active layer; deposition of this layer is still being optimized.

During activation-controlled, the Butler-Volmer analysis is applicable. A similar analysis has been performed during oxygen reduction on LSM cathodes ${ }^{24}$ using the familiar equation

$$
i=i_{0}\left(\mathrm{e}^{\alpha_{\mathrm{a}} \eta F / R T}-\mathrm{e}^{-\alpha_{\mathrm{c}} \eta F / R T}\right)
$$

In this equation, $R, T$, and $F$ have their usual thermodynamic meaning, $i$ is the measured current density, $i_{0}$ is the exchange current density, $\eta$ is the overpotential, and $\alpha_{\mathrm{a}}$ and $\alpha_{\mathrm{c}}$ are the anodic and cathodic charge-transfer coefficients, respectively. Under the conditions of activation control, both the low-field (LF, low overpotentials) and high-field (HF, high overpotentials) regions can be used for kinetic analysis.

At the high overpotentials associated with the HF region, the reverse electrochemical reaction is assumed to be occurring at a negligible rate. As a result, this simplifying assumption results in Eq. 2, yielding a linear Tafel plot $(\eta v s . \log i)$

$$
\log i=\frac{\alpha_{\mathrm{a}} F \eta}{R T}+\log i_{0}
$$

If it is assumed that the first electron-transfer step of a reaction mechanism is rate determining, the high-field region is expected to commence at about $\pm 100 \mathrm{mV}$ at room temperature (with $<1 \%$ error), while at $800^{\circ} \mathrm{C}$, this increases to $\pm 400 \mathrm{mV}$. However, these onset potentials are lowered when rate-limiting steps occur later in a sequence of reaction steps. For these SD Ni-YSZ anodes, the Tafel region appears to commence at an overpotential of $100 \mathrm{mV}$, as evidenced in Fig. 7b, suggesting that a later step in the mechanism is rate-determining.

The $i_{0}$ values, obtained by extrapolation of the Tafel plot (Eq. 3) to zero overpotential, were found to decrease from 390 to 270 $\mu \mathrm{A} / \mathrm{cm}^{2}$ over the analysis time of Fig. 7. This may suggest that an unusual mechanistic change occurs at higher currents (overpotentials), or possibly that an inhibiting effect of electrode porosity is being experienced. ${ }^{25}$ Interestingly, there is also a slight decrease in the Tafel slope derived from Fig. 7b, which drops from 310 to 285 $\mathrm{mV} / \mathrm{dec}$ of current over the time of $4 \mathrm{~h}$ and 24 scans. To compare, for a mechanism with an initial electron transfer as the rate-limiting step, the Tafel slope would be expected to be $427 \mathrm{mV} / \mathrm{dec}$ of current at $800^{\circ} \mathrm{C}$. A Tafel slope of $213 \mathrm{mV} / \mathrm{dec}$ would be expected for a reaction with a rapid first electron transfer followed by a rate-limited chemical step, while a Tafel slope of $142 \mathrm{mV} / \mathrm{dec}$ would be expected for a reaction with a rapid electron transfer, followed by a second electron transfer. The measured Tafel slope does not agree with any of these options, and this irregular result is discussed further.

In the $\mathrm{LF}$ region there is little perturbation from the $\mathrm{OCP}$, and as $\eta$ is small, this allows the valid linearization of the Butler-Volmer equation, consistent with the linear $i / E$ relationship seen on either side of $0 \mathrm{~V}$ derived from Fig. $7 \mathrm{a}$

$$
i / \eta=\frac{F}{R T} \frac{n}{v} i_{0}
$$

where $n$ is the total number of electrons transferred in the overall reaction, and $v$ is the stoichiometric coefficient, the number of times the rate-determining step occurs. The $n / v$ term in Eq. 3 stems from the relationship, $n / v=\alpha_{\mathrm{a}}+\alpha_{\mathrm{c}}$, which is used when the $\alpha_{\mathrm{a}}$ and $\alpha_{\mathrm{c}}$ values are unknown or when the reaction mechanism is presumed to be multistep in nature. ${ }^{26}$

Often, $n / v$ is assumed to be 1 for the calculation of $i_{0}$. Using this assumption at room temperature, the LF region should span $\pm 10 \mathrm{mV}$ overpotential, allowing for an error of less than $1 \%$, while at the elevated working temperature of these experiments $\left(800^{\circ} \mathrm{C}\right)$, the $\mathrm{LF}$ region will extend between -40 and $40 \mathrm{mV}$. Using the assumption that $n / v=1, \mathrm{LF} i_{0}$ values were calculated from Eq. 3 for

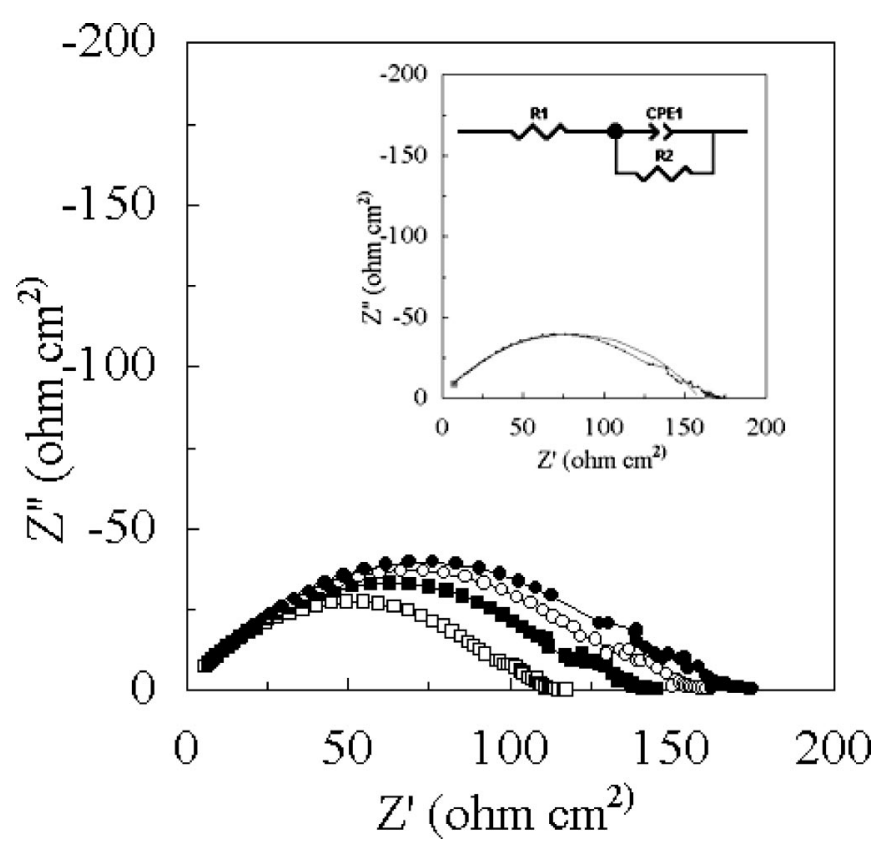

Figure 8. Nyquist data for $\mathrm{H}_{2}$ oxidation in $97: 3 \mathrm{H}_{2}: \mathrm{H}_{2} \mathrm{O}$ at $800^{\circ} \mathrm{C}$ at SD $\mathrm{NiO}-\mathrm{YSZ}$ on YSZ disk electrolyte, all collected at the OCP, following $5 \mathrm{~min}$ of polarization at $(\square) 0,(\square) 100,(\bigcirc) 200$, and $(\mathbf{\square}) 300 \mathrm{mV}$.

hydrogen oxidation at SD Ni-YSZ and were found to decrease from 830 to $585 \mu \mathrm{A} / \mathrm{cm}^{2}$ over the series of scans shown in Fig. 7a. A comparison of the LF $i_{0}$ values with those obtained from HF shows that LF $i_{0}$ values are larger, by a little more than a factor of two, than those determined from HF analysis. Therefore, the LF $i_{0}$ values were recalculated using $n / v$ of 2 , giving values of $415 \mu \mathrm{A} / \mathrm{cm}^{2}$, decreasing to $290 \mu \mathrm{A} / \mathrm{cm}^{2}$, which compare well with the HF $i_{0}$ values given previously.

Mechanistically, the assumption that $n / v$ is 2 can be easily explained for the hydrogen oxidation reaction that occurs at the anode. As there are only two electrons transferred in total, $n$ and $v$ must be 2 and 1, respectively. This interpretation is consistent with the following mechanism

$$
\begin{gathered}
\mathrm{H}_{2}+\mathrm{O}^{2-} \rightleftarrows \mathrm{OH}^{-}+\mathrm{H}_{\mathrm{ads}}+\mathrm{e}^{-} \quad \text { (fast) } \\
\mathrm{H}_{\mathrm{ads}}+\mathrm{OH}^{-} \rightarrow \mathrm{H}_{2} \mathrm{O}+\mathrm{e}^{-} \quad \text { (slow) }
\end{gathered}
$$

For this mechanism, the measured Tafel slope is expected to be $142 \mathrm{mV} / \mathrm{dec}$ of current at $800^{\circ} \mathrm{C}$. The experimental slopes of 285 $\mathrm{mV} / \mathrm{dec}$, at their lowest, are approximately double the predicted value, perhaps related to the porosity ${ }^{25}$ of the anode layer or indicative of a more complex reaction mechanism involving the adsorption of intermediates. ${ }^{27}$

The EIS data also show a decrease in performance over the time of these experiments. Figure 8 shows a series of Nyquist plots, collected at the OCP, where an increasing diameter of the arc is indicative of reduced performance. Scan 1 was collected prior to any electrochemical testing, whereas scans 2- to 4 were taken following the CVs shown in Fig. 7 and after brief periods of polarizations at 100, 200, and $300 \mathrm{mV}$. Notably, even when a series of EIS data sets were collected only at the OCP without intermittent CVs, there was still a tendency for a decrease in performance, typically between 4 and $9 \%$ per scan. The cause for this loss of performance is still under investigation but appears to be partly due to the thin active layer on these electrodes, which may be less stable than desired.

To obtain $i_{0}$ from the EIS data, the charge-transfer resistance was first obtained by fitting the data to an equivalent circuit (EC). In the present work, a simple R1-R2/CPE circuit, shown in the inset of Fig. 8, was used. Also shown as another inset to Fig. 8 is the good fit 


\begin{tabular}{|c|c|c|c|c|}
\hline & $\mathrm{LF} i_{0}\left(\mu \mathrm{A} / \mathrm{cm}^{2}\right)$ & $\mathrm{HF} i_{0}\left(\mu \mathrm{A} / \mathrm{cm}^{2}\right)$ & $\operatorname{EIS} i_{0}\left(\mu \mathrm{A} / \mathrm{cm}^{2}\right)$ & Tafel slope \\
\hline SD & $415-290$ & $390-270$ & $415-245$ & $310-285$ \\
\hline CG & $40-60$ & $35-60$ & $40-57$ & $195-210$ \\
\hline
\end{tabular}

${ }^{\mathrm{a}}$ In first $3 \mathrm{~h}$ of electrochemical evaluation.

obtained from one set of data to the selected EC. R1 is due to series resistors, such as that originating from the electrolyte between the WE and RE, contacts, cables, etc. R2 yields $i_{0}$ and the values obtained from R2 were similar in both magnitude and trends to those calculated from the LF analysis above. For $n / v=2$, the initial $i_{0}$ value is $415 \mu \mathrm{A} / \mathrm{cm}^{2}$, dropping to $245 \mu \mathrm{A} / \mathrm{cm}^{2}$ at the end of the experiment.

Using the same electrochemical techniques and cell design, experiments have also been carried out on CG Ni-YSZ composite anodes for comparative purposes (Table I). Their $i_{0}$ values increased during the course of testing, although the final values are still well below those measured for our as-yet unoptimized SD materials. The LF $i_{0}$ values were calculated using $n / v=2$, as calculations using $n / v=1$ again showed a twofold disagreement between the LF and HF $i_{0}$ values, similar to the SD materials. As can be seen from Table I, the CG material has a lower Tafel slope than the SD material, closer to what is expected based on the suggested mechanism of Eq. 4. Overall, however, an approximate ten-fold improvement in the $\mathrm{H}_{2}$ oxidation activity is seen at our SD materials compared to the CG anodes during initial testing, although the differences became somewhat smaller with time of operation.

\section{Conclusions}

The successful synthesis and electrochemical characterization of SD NiO-YSZ particles demonstrates the excellent potential of these materials as catalysts for SOFC applications. SD NiO and YSZ were easily and rapidly produced from metallic nitrate and butoxide precursors, forming a dispersed nanoparticulate sol in the case of $\mathrm{NiO}$, or a gel in the case of YSZ. If desired, YSZ gel formation can be inhibited using acid, so that the nanoparticulate sol remains. All these materials are easily dried and can withstand heat-treatments of at least $1000^{\circ} \mathrm{C}$ while retaining small particle sizes.

After heat-treatment at $1000^{\circ} \mathrm{C}$, the $\mathrm{NiO}$ and $\mathrm{YSZ}$ average particle sizes were found to be below 50 and $30 \mathrm{~nm}$, respectively, as measured using XRD and TEM. In each case there appeared to be some agglomeration of particles to produce larger structures, although small particles could generally be seen within the large agglomerates. Structurally, NiO particles appeared to have welldefined edges when compared to YSZ particles, which looked less crystalline in appearance.

Spray coat application of the YSZ SD-powder to pressed YSZ disks prior to disk firing was found to enhance the adhesion of the NiO-YSZ composite powders, likely by roughening the YSZ disk surface. While not yet optimized, these anode layers are between 5 and $10 \mu \mathrm{m}$ in thickness, although the relative thickness of the NiOYSZ composite active layer compared to the $\mathrm{NiO}$ current collecting layer has not yet been determined.

Both low- and high-field CV, as well as impedance spectroscopy, were employed in a half-cell configuration to assess the electrochemical performance of these SD anode layers at $800^{\circ} \mathrm{C}$ in $97: 3$ $\mathrm{H}_{2}: \mathrm{H}_{2} \mathrm{O}$. The exchange current density, obtained from all three methods, was found to agree only if a two-step reaction was assumed, with the slow step occurring only once in the reaction of one molecule of hydrogen. Further, the relatively low Tafel slope obtained suggests that a second electron transfer step may be rate limiting.

By comparison with CG Ni-YSZ, our results indicate an initial tenfold higher hydrogen oxidation activity for the SD Ni-YSZ. Even so, there is good agreement between the inferred reaction mechanism at the SD and CG electrodes. However, a gradual loss of performance was observed for the SD electrodes that was not seen with the CG materials, possibly attributed to the thinness of the SD active layer. To overcome this loss of activity, fabrication of the SD anode will be further optimized in near future work.

\section{Acknowledgments}

We gratefully acknowledge the overall financial support of the Natural Sciences and Engineering Research Council of Canada (NSERC), as well as scholarship support for P.G.K. from NSERC and the Alberta Ingenuity Fund. All imaging was performed at the Microscopy and Imaging Facility University of Calgary, and we thank R. Humphrey and Dr. J. Liu for their assistance with these analyses.

The University of Calgary assisted in meeting the publication costs of this article.

\section{References}

1. S. C. Singhal, Solid State Ionics, 135, 305 (2000).

2. N. Q. Minh, J. Am. Ceram. Soc., 76, 563 (1993).

3. O. A. Marina, N. L. Canfield, and J. W. Stevenson, Solid State Ionics, 149, 21 (2002).

4. J.-H. Lee, H. Moon, H.-W. Lee, J. Kim, J.-D. Kim, and K.-H. Yoon, Solid State Ionics, 148, 15 (2002)

5. R. Vaben, D. Simwonis, and D. Stover, J. Mater. Sci., 36, 147 (2001)

6. G.-Q. Shao, H. Cai, J.-R. Xie, X.-L. Duan, B.-L. Wu, R.-Z. Yan, and J.-K. Guo, Mater. Lett., 57, 3287 (2003).

7. M. Mamak, N. Coombs, and G. Ozin, Adv. Mater. (Weinheim, Ger.), 12, 198 (2000).

8. M. Mamak, N. Coombs, and G. Ozin, Chem. Mater., 13, 3564 (2001).

9. S. T. Aruna and K. S. Rajam, Scr. Mater., 48, 507 (2003).

10. M. Mamak, N. Coombs, and G. Ozin, Chem. Commun. (Cambridge), 20, 2300 (2002).

11. F. H. Moser and N. R. Lynam, U.S. Pat. 4,959,247 (1990).

12. S.-G. Kim, S. W. Nam, S.-P. Yoon, S.-H. Hyun, J. Han, T.-H. Lim, and S.-A. Hong, J. Mater. Sci., 39, 2683 (2004).

13. S. H. Chan, X. J. Chen, and K. A. Khor, J. Appl. Electrochem., 31, 1163 (2001).

14. J. Winkler, P. V. Hendriksen, N. Bonanos, and M. Mogensen, J. Electrochem. Soc. 145, 1184 (1998)

15. D. Simwonis, F. Tietz, and D. Stover, Solid State Ionics, 132, 241 (2000).

16. R. Wilkenhoener, R. Vaben, H. P. Buchkremer, and D. Stover, J. Mater. Sci., 34, 257 (1999)

17. T. Fukui, S. Ohara, M. Naito, and K. Nogi, J. Power Sources, 110, 91 (2002).

18. S. T. Aruna, M. Muthuraman, and K. C. Patil, Solid State Ionics, 111, 45 (1998).

19. M. Marinsek, K. Zupan, and J. Mà̀ek, J. Power Sources, 106, 178 (2002).

20. J. Fournier, J. Liu, and V. I. Birss, J. Electrochem. Soc., In preparation.

21. F. Tietz, F. J. Dias, D. Simwonis, and D. Stover, J. Eur. Ceram. Soc., 20, 1025 (2000).

22. S. Primdahl and M. Mogensen, J. Appl. Electrochem., 30, 24 (2000).

23. M. Guillodo, P. Vernoux, and J. Fouletier, Solid State Ionics, 127, 99 (2000).

24. A. C. Co, S. J. Xia, and V. I. Birss, in Solid Oxide Fuel Cells, S. C. Singhal and M. Dokiya, Editors, PV 2003-7, p. 478, The Electrochemical Society Proceedings Series, Pennington, NJ (2003).

25. R. De Levie, in Advances in Electrochemistry and Electrochemical Engineering, Vol. 6, P. Delahay, Editor, p. 329, Interscience Publishers/John Wiley \& Sons, New York (1967).

26. J. O'M Bockris and A. K. N. Reddy, Modern Electrochemistry, 2A Fundamentals of Electronics, 2nd ed., p. 1053, Kluwer Academic/Plenum Publishers, New York (2000).

27. C. F. Zinola, A. M. Castro Luna, W. E. Triaca, and A. J. Arvia, Electrochim. Acta, 11/12, 1627 (1994). 